\title{
Plains lubber grasshopper (Brachystola magna) as a potential intermediate host for Oxyspirura petrowi in northern bobwhites (Colinus virginianus)
}

\author{
WHITNEY M. KISTLER ${ }^{1}$, SABRINA HOCK ${ }^{1}$, BEATRICE HERNOUT ${ }^{1}$, EVAN BRAKE ${ }^{1,2}$, \\ NIKKI WILLIAMS ${ }^{1,2}$, CARSON DOWNING ${ }^{1,2}$, NICHOLAS R. DUNHAM ${ }^{1}$, \\ NAVEEN KUMAR ${ }^{1}$, UDAY TURAGA ${ }^{1}$, JULIE A. PARLOS ${ }^{1}$ and RONALD J. KENDALL ${ }^{1}$ * \\ ${ }^{1}$ Wildlife Toxicology Laboratory, The Institute of Environmental and Human Health, Texas Tech University, Box 41163, \\ Lubbock, Texas 79409, USA \\ ${ }^{2}$ Department of Natural Resources Management, Texas Tech University, 2500 Broadway, Lubbock, Texas 79409, USA
}

(Received 4 April 2016; accepted 12 April 2016)

\begin{abstract}
SUMMARY
Oxyspirura petrowi is a heteroxenous parasitic nematode that has been reported in high prevalences from birds in the Order Galliformes experiencing population declines in the USA. There is a paucity of information regarding the natural history $O$. petrowi, including the life cycle and effects of infection on wild bird populations. In order to study the life cycle of this parasite, we collected plains lubber grasshoppers (Brachystola magna) from a field location in Mitchell County, Texas. We found third-stage larvae (L3) in 37.9\% (66/174) B. magna. We determined that they were O. petrowi through morphological comparison of L 3 from experimentally infected Acheta domesticus and by sequence analysis. Then, we showed that $B$. magna are a potential intermediate hosts for $O$. petrowi infections in northern bobwhites (Colinus virginianus) in a laboratory setting by experimental infection. We first detected shedding of eggs in feces using a fecal float technique 52 days post infection. In addition, we recovered $87 \mathrm{O}$. petrowi from experimentally infected northern bobwhites. Although we detected shedding in feces, recovery of eggs was low ( $>5$ eggs $/ \mathrm{g}$ ). Future work is needed to understand shedding routes and shedding patterns of northern bobwhites infected with $O$. petrowi.
\end{abstract}

Key words: birds, Galliformes, grasshopper, intermediate host, life cycle, northern bobwhite, Orthoptera, Oxyspirura petrowi.

\section{INTRODUCTION}

Parasites of the genus Oxyspirura (Spirurida: Thelaziidae) are heteroxenous nematodes that primarily use avian species as definitive hosts (Addison and Anderson, 1969). Oxyspirura spp. have been reported from more than 80 avian species worldwide (Addison and Anderson, 1969). Despite many published records of Oxyspirura spp. in bird species across the globe, very little is known about their life cycle. Of the approximately 72 species of Oxyspirura reported, the life cycle is only known in one species that infects birds, Oxyspirura mansoni.

The life cycle of O. mansoni was described by three separate studies in the 1920s (Fielding, 1927; Kobayashi, 1927; Sanders, 1928). The definitive host was determined to be the chicken (Gallus gallus) and the intermediate host is the Surinam cockroach (Pycnoscalus surinamensis; Dictyoptera: Blattodea). Sexually mature O. manson $i$ are found under the nictitating membranes, in conjunctival sacs, and nasallacrimal ducts of chickens (Schwabe, 1951). Eggs are

* Corresponding author: Wildlife Toxicology Laboratory, The Institute of Environmental and Human Health, Texas Tech University, Box 41163, Lubbock, Texas 79409, USA. Tel: 806-885-0238. E-mail: ron. kendall@ttu.edu passed through the nasal-lacrimal ducts into the mouth and then swallowed before being passed in the feces (Fielding, 1927). Cockroaches are infected from ingesting eggs or recently hatched first-stage larvae (L1) and O. mansoni develop into infective third-stage larvae (L3) in approximately 50 days (Fielding, 1927; Schwabe, 1951). A similar life cycle can be inferred with $O$. conjunctivalis using the speckled cockroach (Nauphoeta cinerea; Dictyoptera: Blattodea) as an intermediate host and primates as definitive hosts (Ivanova et al. 2007); however, complete time for development was not analysed.

Recently Oxyspirura petrowi has received attention due to the high prevalences detected in native Galliformes species with declining populations in the USA (Robel et al. 2003; Dunham et al. 2014). These population declines are multi-factorial and include habitat loss and fragmentation, climatic variables and other factors (Johnson et al. 2004; Parent et al. 2016; Rho et al. 2015). The direct impacts of $O$. petrowi on wild populations are currently unknown; however, a histopathology study has described lesions present on the cornea, lacrimal gland and Harderian gland in infected birds (Bruno et al. 2015). These lesions indicate that there is the potential for $O$. petrowi to affect the eyesight of infected birds, which could affect their

Parasitology Open (2016), Vol. 2, e7; page 1 of 8. (C) Cambridge University Press 2016. This is an Open Access article, distributed under the terms of the Creative Commons Attribution-NonCommercial-NoDerivatives licence (http://creativecommons.org/licenses/by-nc-nd/ $4.0 /$ ), which permits non-commercial re-use, distribution, and reproduction in any medium, provided the original work is unaltered and is properly cited. The written permission of Cambridge University Press must be obtained for commercial re-use or in order to create a de- 
ability to forage or escape predators. Although $O$. petrowi has been detected in several species of birds, no studies have looked for intermediate hosts (Pence, 1972, 1975; Dancak et al. 1982; Robel et al. 2003, 2005; Calegaro-Marques and Amato, 2013). The objectives of this study were to: (1) identify a potential intermediate hosts for $O$. petrowi infection in northern bobwhites (Colinus virginianus) in Western Texas; (2) establish experimental infection methods for $O$. petrowi in northern bobwhites; and (3) determine time for development of $O$. petrowi $\mathrm{L} 3$ to adults in experimentally infected northern bobwhites.

\section{MATERIALS AND METHODS}

\section{Field sampling}

We focused our sampling on plains lubber grasshoppers (Brachystola magna) based on a pilot study indicating they were naturally infected with $O$. petrowi. We identified B. magna using an online key (Brust et al. 2014). We collected B. magna using sweep nets and by hand from a field location in Mitchell County, Texas from 12 May 2015 to 28 August 2015. This location was chosen because of previous and ongoing research showing current $O$. petrowi infection in northern bobwhites (Dunham et al. 2014). After collection, grasshoppers were stored in aerated containers and transported to the laboratory for dissection.

\section{Larvae collection}

We euthanized grasshoppers by placing them at $4{ }^{\circ} \mathrm{C}$ then decapitating them with a pair of scissors. We then dissected the grasshoppers, pinned the grasshoppers open, and examined the grasshoppers under a dissecting microscope for free moving larvae and larvae still in capsules, as previously reported for the development of $O$. mansoni and $O$. conjuctivalis in intermediate hosts (Sanders, 1928; Ivanova et al. 2007). After we examined the grasshoppers for larvae, we then placed the grasshoppers into a Petri dish containing $1 / 4$ Ringer's solution (Sigma-Aldrich LLC) and incubated for approximately $30 \mathrm{~min}$ to $1 \mathrm{~h}$ at $37^{\circ} \mathrm{C}$ (Fielding, 1927). We then examined the contents of the Petri dish under a dissecting microscope for free moving larvae. We collected larvae using a pipette for use in morphological and molecular analysis. Briefly, all L3 were examined under a dissecting microscope for to ensure collected L3 were morphological similar to each other. Then we collected two L3 from each infected grasshopper for molecular identification. We used the remaining L 3 for morphological identification and experimental infections. In addition, we collected the intestines and reproductive tract from each grasshopper after incubation and placed them into a $2 \mathrm{~mL}$ microcentrifuge tube for DNA extraction and subsequent molecular analysis.

\section{Experimental infection of Acheta domesticus}

To be able to compare the morphology of L3 from grasshoppers caught in the field to $O$. petrowi $\mathrm{L} 3$, we experimentally infected $30 \mathrm{~A}$. domesticus (house crickets; PetsMart Inc., Phoenix, AZ, USA) with gravid female $O$. petrowi containing eggs with visible L1. Briefly, $A$. domestics were stored individually in $152.4 \times 76.2 \times 76.2 \mathrm{~mm}^{3}$ containers with a mesh cover and food deprived for $12 \mathrm{~h}$. Then we placed a depressed glass slide containing one gravid female $O$. petrowi in water in each container until the cricket fed on the nematode. We assumed the nematode was ingested by the cricket if no evidence of the nematode was found on the slide or in the container with the cricket. After feeding on $O$. petrowi, we placed the cricket on Fluker's Farms Orange Cube diet (Fluker's Farms, Port Allen, LA, USA) until they were dissected or died. We dissected A. domesticus and collected L3, intestines, and the reproductive tracts as described above for B. magna. It is important to note that we could not verify $A$. domesticus were not infected prior to our infection; however, we feel this case is highly unlikely. Acheta domesticus used in this study were raised in captivity and likely had little or no contact with bird feces contaminated with $O$. petrowi eggs.

\section{Identification of larvae and molecular testing of Brachystola magna}

We compared the morphology of L3 collected from both $B$. magna and $A$. domesticus by clearing the larvae in 5\% glycerin and $95 \%$ ethanol solution and observing under 100× using EVOS XL microscope (Thermo Fisher Scientific Inc.). We took measurements of larvae from photographs using Gimp v2.8 (Gimp developing team). In addition to using morphology for identification of L3 from $B$. magna, we used PCR and sequencing to aid in our identification.

We extracted DNA from L3, B. magna and $A$. domesticus using Qiagen DNeasy blood and tissue kits (Qiagen, Germantown, MD, USA). We included a negative extraction sample of PBS every 12 th sample. The PCR reaction was done at $25 \mu \mathrm{L}$ volumes with the primers OXY_ITS2F (5'CTTAGCGGTGGATCACTTGG-3') and the previously published primer QEW_2578R (Xiang et al. 2013). These primers were designed to amplify a 244 base pair region of the ITS2 locus. Each reaction included $5 \mu \mathrm{L}$ of DNA in $20 \mu \mathrm{L}$ of master mix containing $11 \mu \mathrm{L}$ of $\mathrm{H}_{2} \mathrm{O}, 1.5 \mathrm{~mm}$ $\mathrm{MgCl}_{2}, 0.4 \mathrm{~mm}$ each dNTP (Promega, Madison, WI, USA), $0.5 \mu \mathrm{M}$ each primer, and $1.25 \mathrm{U}$ of GoTaq $^{\circledR}$ DNA Polymerase (Promega). Cycling 
parameters were $95^{\circ} \mathrm{C}$ for $3 \mathrm{~min}$ followed by 20 cycles of $95^{\circ} \mathrm{C}$ for $30 \mathrm{~s}, 50^{\circ} \mathrm{C}$ for $30 \mathrm{~s}, 72^{\circ} \mathrm{C}$ for $45 \mathrm{~s}$ and a final extension of $72{ }^{\circ} \mathrm{C}$ for $10 \mathrm{~min}$. We then analysed PCR products on a $1.75 \%$ agarose gel and we sent 29 PCR products (one L 3 from $A$. domesticus and $28 \mathrm{~L} 3$ from different B. magna) to Molecular Cloning Laboratories (MCLAB LLC, South San Francisco, CA, USA) for bidirectional sequencing. Chromatogram data were analysed using Sequencher v 5.1 (Gene Codes, Ann Arbor, MI, USA). We compared sequences from this study to previously published sequences using the blast function available through the National Center for Biotechnology Information (NCBI, Bethesda, MD, USA). In instances where only one L3 was recovered, we used it for molecular testing.

\section{Experimental infections of northern bobwhites}

To determine whether B. magna were suitable intermediate hosts for $O$. petrowi in northern bobwhites, we conducted two experimental infection trials. In the first trial, we fed four, previously uninfected, pen-raised northern bobwhites $B$. magna that contained free moving L3. Prior to feeding, we determined B. magna were infected by partial dissection. Each bird was fed one grasshopper (without head and legs); however, we were unable to accurately quantify the larvae in each grasshopper. We euthanized grasshopper infected birds; one bird at 30 days post infection (dpi); one bird at $44 \mathrm{dpi}$; one bird at $45 \mathrm{dpi}$ and one bird at $70 \mathrm{dpi}$. After euthanasia, we dissected the birds and collected nematodes from the orbital cavity as previously described (Dunham et al. 2014). We then morphologically identified nematodes found in the orbital cavity of the infected northern bobwhites as $O$. petrowi based on: undivided buccal capsule; oesophagus not clearly divided into muscular and glandular portions; unequal spicules; and absence of gubernaculum (Addison and Anderson, 1969; Pence, 1972). We also amplified a partial 244 base pair region of the ITS2 locus using the same PCR described above.

In order to control the dose of infection, we collected L3 from B. magna to examine another infection method. Briefly, L3 were collected by pipette from Petri dishes after incubation and placed into a $2 \mathrm{~mL}$ microcentrifuge tube. We then infected five northern bobwhites: one with ten larvae; two with 20 larvae; and two with 40 larvae in $400 \mu \mathrm{L}$ of Ringer's solution by oral gavage. All experimental infections were done the same day L3 were collected. We inoculated two additional birds with $400 \mu \mathrm{L}$ Ringer's solution to act as uninfected negative controls. We selected these infection doses because they are representative of worm burdens observed in wild caught northern bobwhites (Dunham et al. 2014). We did not euthanize any of the gavage infected birds because they are being used in a larger ongoing study. This was done to reduce the overall number of birds used in experimental trials. We monitored birds for $90 \mathrm{~min}$ post-infection to ensure they did not regurgitate the grasshoppers or the gavage and monitored birds daily throughout the study for any clinical signs of disease (ruffled feathers, lethargy, ataxia, diarrhoea, etc.). We collected fecal samples from each bird daily to detect egg shedding using a fecal float procedure using the Cornell-Wisconsin egg-counting double centrifugation procedure (Zajac et al. 2012) with a magnesium sulphate $\left(\mathrm{MgSO}_{4}\right.$; specific gravity $\left.=1.31\right)$ fecal float solution. Briefly, we mixed the fecal sample with deionized water, poured through a $200 \mu \mathrm{m}$ sieve into a $15 \mathrm{~mL}$ conical tube, and centrifuged for $5 \mathrm{~min}$ at $500 \mathrm{~g}$. We then poured off the supernatant and resuspended the pellet in $\mathrm{MgSO}_{4}$ and vortexed. Next we centrifuged the sample for $5 \mathrm{~min}$ at $500 \mathrm{~g}$ with the centrifuge brake turned off. After letting the coverslip remain on the tube for $5 \mathrm{~min}$, we carefully examined each field of the slide under $100 \times$. We included fecal samples through $70 \mathrm{dpi}$.

\section{Statistical analysis}

We analysed the prevalence of PCR positives by month with logistic regression using robust standard errors and we analysed L3 burden in grasshoppers by negative binomial regression using robust standard errors. We considered a sample PCR positive if either the grasshopper was PCR positive or if a collected L3 from the grasshopper was PCR positive. We conducted analyses using Rv3.2.4 (www.rproject.org) using the $\operatorname{glm}()$ and $g \operatorname{lm} . n b()$ functions and the package sandwich v2.3 for implementing robust standard error estimates.

\section{RESULTS}

\section{Brachystola magna natural infections}

We detected L3 in $37.9 \%(64 / 174)$ of B. magna by dissection and incubation. The first L3 we detected in naturally infected B. magna was on the 17 th of June. Based on PCR, we detected an additional seven $B$. magna infected with $O$. petrowi, with the earliest being detected on the 13th of May. We did not detect any L3 in these seven B. magna based on dissection or incubation. The highest PCR prevalence and L3 burden of $O$. petrowi infections in $B$. magna were in August and lowest PCR prevalence and L3 burdens were in May (Table 1). During dissection of B. magna, we detected L3 in capsules along the body wall (Fig. 1) and moving freely throughout the body cavity. Based on dissection alone, we detected L3 in $17.8 \%(31 / 174)$ of $B$. magna; however after incubation, we detected L3 from an additional $33 \mathrm{~B}$. magna. The average L3 recovered from infected grasshoppers was $9.8 \mathrm{L3} /$ 
Table 1. Results of logistic regression of PCR prevalence by month and negative binomial regression of thirdstage larvae burden by month.

\begin{tabular}{|c|c|c|c|c|}
\hline Month & $\begin{array}{l}\text { Grasshoppers infected } \\
\text { with third-stage larvae/ } \\
\text { grasshoppers sampled }(\%)^{\text {a }}\end{array}$ & $\begin{array}{l}\text { Coefficients } \pm \text { standard } \\
\text { error } \\
\text { Odds ratios (95\% } \\
\text { confidence intervals) }\end{array}$ & $\begin{array}{l}\text { Third-stage larvae/ } \\
\text { infected grasshopper } \\
\text { Mean (range) }\end{array}$ & $\begin{array}{l}\text { Coefficients } \pm \text { standard } \\
\text { error } \\
\text { Incidence rate ratios }(95 \% \\
\text { confidence intervals) }\end{array}$ \\
\hline May & $1 / 23(4.3)$ & $\begin{array}{l}-2.14 \pm 0.6 \\
0.1(0.0-1.3)\end{array}$ & $\begin{array}{l}0 / 0 \\
0\end{array}$ & $\begin{array}{l}-19.8 \pm 0.6 * * * \\
0\end{array}$ \\
\hline June & $5 / 18(27.7)$ & Referent ${ }^{\mathrm{b}}$ & $\begin{array}{l}26 / 4 \\
6.5(3-13)\end{array}$ & Referent \\
\hline July & $23 / 70(32.9)$ & $\begin{array}{l}0.2 \pm 0.7 \\
1.2(0.3-4.8)\end{array}$ & $\begin{array}{l}94 / 18 \\
5.2(1-21)\end{array}$ & $\begin{array}{l}-0.2 \pm 0.7 \\
0.8(0.2-3.3)\end{array}$ \\
\hline August & $44 / 63(69.8)$ & $\begin{array}{l}2.1 \pm 0.7 * * \\
8.2(2.1-32.2)\end{array}$ & $\begin{array}{l}532 / 44 \\
12.1(1-90)\end{array}$ & $\begin{array}{l}1.6 \pm 0.6 * * \\
5.2(1.6-16.9)\end{array}$ \\
\hline
\end{tabular}

**** $P=0$.

$* * P<0.001$.

a Includes seven PCR positive samples one in May, one in June, and five in July. We did not recover any third-stage larvae from these grasshoppers.

b Comparison group.

grasshopper (9.0-10.6 95\% CI; range 1-90). We did observe 'sausage-like' larvae similar to the description of second stage Thelazia callipaeda described by Otranto et al. (2005); however, we were not able to amplify $O$. petrowi DNA from those samples and therefore did not include them in our analyses.

\section{Acheta domesticus experimental infections}

We did not find evidence of the gravid $O$. petrowi in all 30 cages and therefore assumed all $A$. domesticus fed on the nematode. Seven A. domesticus died within 7 dpi. We subsequently dissected and ran PCR on these A. domesticus, but did not detect

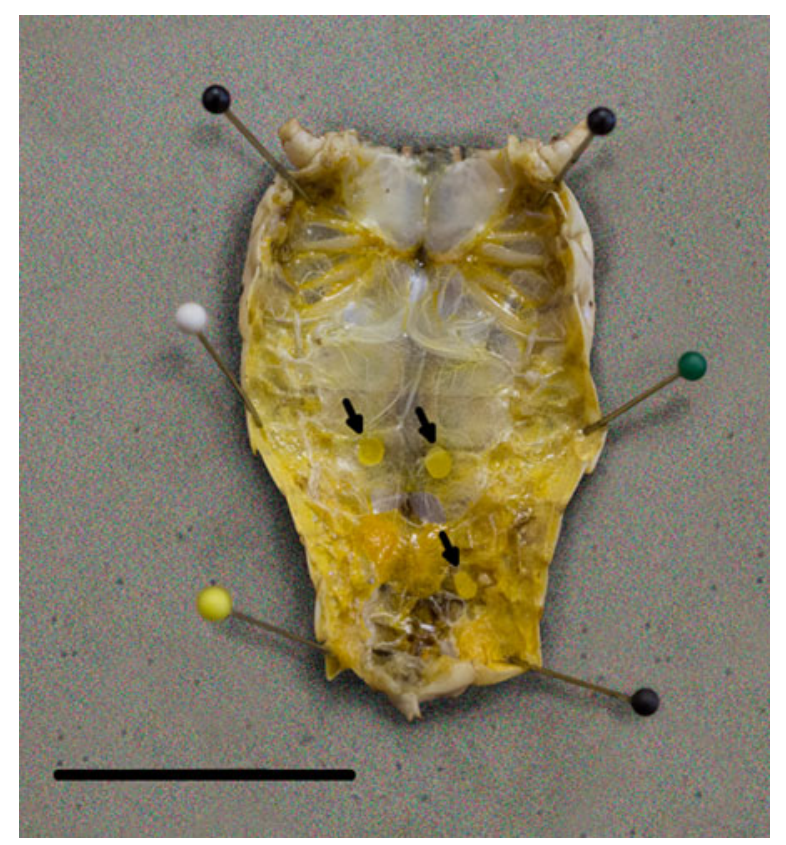

Fig. 1. Encapsulated third-stage larvae in Brachystola magna. Capsules $(n=3)$ are marked with arrows. Scale bar $20 \mathrm{~mm}$. evidence of $O$. petrowi infection in any of the seven dead A. domesticus. We euthanized and dissected two $A$.domesticus each on $10,12,14,17,30$ and $40 \mathrm{dpi}$. We did not observe any larvae during the dissection, but did get two PCR-positive result from one A.domesticus from 12 and $30 \mathrm{dpi}$. On $45 \mathrm{dpi}$, we recovered two L3 (based on well-developed intestinal tract and presence of genital stem cells) from one $A$.domesticus. The remaining $A$. domesticus were euthanized and dissected on $47 \mathrm{dpi}(n=4)$ and 48 dpi $(n=5)$. We found an additional three $A$. domesticus infected and recovered a total of eight L3. Including the PCR positive, the infection prevalence was only $16.6 \%(5 / 30)$ from all infected $A$. domesticus. We obtained PCR-positive results from six L3 and sequenced one PCR positive which had a $99 \%$ identity to previously published $O$. petrowi ITS2 sequences (GenBank\# KF110800, KF110799 and KF306222). We used the remaining four L3 for morphological comparison with L3 from B. magna.

\section{Identification of larvae}

We did not detect any significant differences in any of the morphological measurements between L3 collected from A.domesticus and B. magna (Table 2). In addition, we obtained at least one PCR positive from L3 collected from each grasshopper. Furthermore, sequence analysis from $28 \mathrm{~L} 3$ samples from $B$. magna (GenBank\# KT958840-KT958867) revealed a $99-100 \%$ similarity to previously published $O$. petrowi ITS2 sequences (GenBank\# KF110800, KF110799 and KF306222).

\section{Northern bobwhite experimental infections}

All birds were presumed negative for $O$. petrowi infection prior to feeding based on fecal float and all 
Table 2. Morphological characteristics from L3 Oxyspirura petrowi larvae recovered from Acheta domesticus $(n=4)$ and Brachystola magna $(n=24)$.

\begin{tabular}{|c|c|c|}
\hline Measurement & $\begin{array}{l}\text { Acheta domesticus } \\
\text { (95\% confidence } \\
\text { interval) }\end{array}$ & $\begin{array}{l}\text { Brachystola magna } \\
\text { ( } 95 \% \text { confidence } \\
\text { interval) }\end{array}$ \\
\hline Length & $3.11(3.03-3.19)$ & $3.14(2.95-3.34)$ \\
\hline Width & $0.10(0.06-0.14)$ & $0.10(0.09-0.11)$ \\
\hline $\begin{array}{l}\text { Oesophagus } \\
\text { length }\end{array}$ & $0.23(0.19-0.27)$ & $0.28(0.26-0.30)$ \\
\hline $\begin{array}{l}\text { Distance of } \\
\text { nerve ring } \\
\text { from Anterior } \\
\text { end }\end{array}$ & $0.08(0.07-0.09)$ & $0.09(0.08-0.10)$ \\
\hline
\end{tabular}

All measurements in $\mathrm{mm}$.

birds were infected with an unidentified strongylid from the breeder (Fig. 2F). On $30 \mathrm{dpi}$, we euthanized one bird and found $23 \mathrm{O}$. petrowi (13 females and 10 males) in the lacrimal duct and under the nictitating membrane. Morphological examination indicated $O$. petrowi were not sexually mature with male's spicule development incomplete and females with no egg development in the reproductive tract (Fig. 2A and C). We collected six females and four males and 22 males and 25 females from the birds we euthanized 44 and $45 \mathrm{dpi}$, respectively. In these nematodes, we detected morulated eggs in the uteri of the females (Fig. 2D) and spicule development was complete in males (Fig. 2B). We recovered seven adult $O$. petrowi from the bird we euthanized on $70 \mathrm{dpi}$. We observed that both males $(n=5)$ and females $(n=2)$ were fully developed and eggs containing L1 were visible in the reproductive tract of the female (Fig. $2 \mathrm{~B}$ and $\mathrm{E}$ ). We detected one PCR positive from at least one $O$. petrowi recovered from these experimentally infected birds.

We first detected egg shedding at $52 \mathrm{dpi}(n=3)$ and all infected birds, which were not euthanized, shed eggs by $56 \mathrm{dpi}$ (Fig. 2F). The one remaining bird infected by feeding B. magna shed at $55 \mathrm{dpi}$. The average mass of feces used for fecal float analysis was $3.7 \mathrm{~g}(3.5-3.995 \% \mathrm{CI})$. The number of eggs detected with fecal floats throughout the study was low $2.2 \mathrm{eggs} / \mathrm{g}$ of feces $(1.2-3.295 \% \mathrm{CI})$. In order to determine if the poor shedding detection was a result of eggs not passing entirely through the intestinal tract, we collected the contents of the crop, ventriculus, proventriculus, small intestine and cecum in separate containers from the bird euthanized $70 \mathrm{dpi}$. We then performed a float using $\mathrm{MgSO}_{4}$, but we were unable to detect any eggs from the intestinal contents. Finally, we did not detect the presence of blood in the oesophagus or intestinal tract of any of the $O$. petrowi collected during this study.
DISCUSSION

Understanding the natural history and life cycle of $O$. petrowi is an important step in understanding how these nematodes affect wild bird populations. This allows for experimental infection methods that more accurately simulate how infection occurs in wild bird populations in a controlled laboratory setting. Experimental infections increase our understanding of the effects of infection on individual birds and aids in the development of diagnostic tests (quantitative PCR) that can be used to determine infection status in wild birds. In this study, we showed $B$. magna populations are naturally infected with $O$. petrowi in a high prevalence (>35\%). Furthermore, we demonstrated that $B$. magna are suitable intermediate hosts for $O$. petrowi in northern bobwhites through experimental infection. Although our data suggests B. magna are suitable intermediate hosts for $O$. petrowi in a laboratory setting, confirming $B$. magna as the primary intermediate host in a natural setting was outside the scope the current study.

Insects in the order Orthoptera are known to be important components of northern bobwhite diets (Parmalee, 1953; Rollins, 1980); however, to our knowledge, no studies have recorded $B$. magna being used as a food source by northern bobwhites. The majority of studies that have analysed diets in northern bobwhites do not report arthropod genera, but simply report insect food sources as animal matter or only identify them to order (Wood et al. 1980; Harveson et al. 2004). We believe it is possible that northern bobwhites can utilize B. magna as a food source because: unlike other lubber grasshoppers B. magna that are nontoxic to vertebrates (Burleson, 1974; Bright et al. 1994); other large grasshopper species of similar size (e.g. Schistocerca americana and Melanoplus spretus) have been reported in diet studies of quail (Judd, 1905); and the range of B. magna overlaps with northern bobwhites (Brust et al. 2014). These qualities may make them a potential food source for northern bobwhites, particularly when females are nesting and their protein requirements are high, but foraging time is brief (Host and Physics, 2015). The perceived increased L3 burden of infected B. magna in August may be related to the increased time for development and development to L3 later in the year, which would make them easier to detect.

Our experimental infection and the resulting development of $O$. petrowi in $A$. domesticus are hard to interpret. On one hand, we were only able to detection $O$. petrowi infection in 5/30 experimentally infected $A$. domesticus and our L3 burden was lower than in naturally infected $B$. magna. However, we do not know if this is a result of $A$. domesticus being poor intermediate hosts or a result of an inadequate infection method. In a natural 


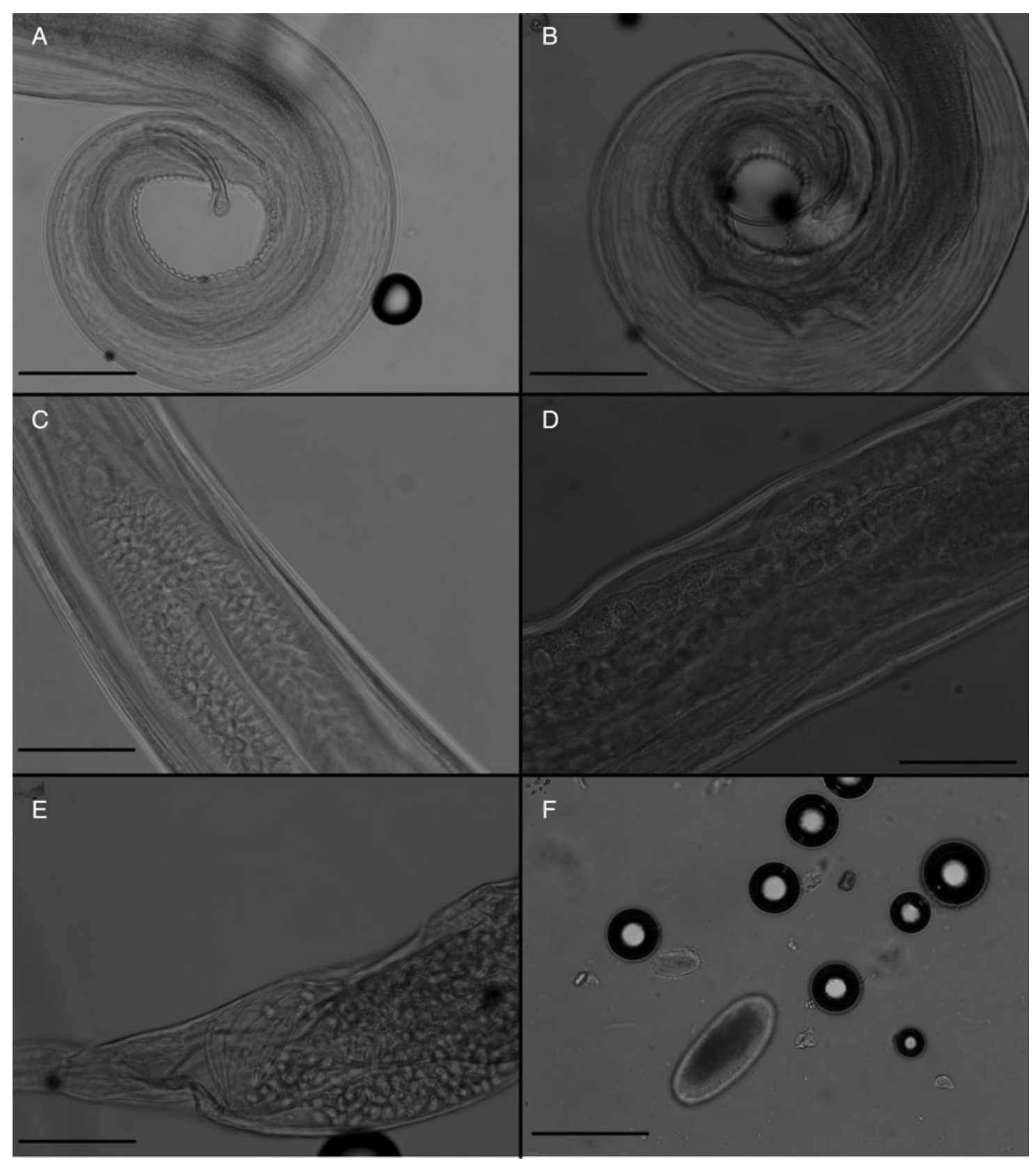

Fig. 2. Comparison of Oxyspirura petrowi recovered from experimentally infected northern bobwhite (Colinus virginianus): (A) male O. petrowi $30 \mathrm{dpi}$. Short spicule green arrow and long spicule black arrow; (B) male O. petrowi 70 dpi. Short spicule green arrow and long spicule black arrow; (C) female O. petrowi $30 \mathrm{dpi}$, note absence of eggs in reproductive tract; (D) female $O$. petrowi $45 \mathrm{dpi}$, note morulated eggs (arrows) in the reproductive tract; (E) female $O$. petrowi $70 \mathrm{dpi}$, note first-stage larvae in eggs (arrows) in the reproductive tract; (F) O. petrowi egg marked with an arrow next to unidentified Strongylid species egg. Scale bars for A, B, E and F are 100 and $50 \mu \mathrm{m}$ for C and D.

infection, $O$. petrowi eggs would be shed by and then passed in feces, which would permit longer time for egg development than our infection method. Previous research on $O$. mansoni has shown the average size of embryonated eggs collected from feces are larger than those collected from the vagina and uteri of gravid female worms, which could support the need for further development before they become infectious. However, experimental infection of Surinam cockroaches with eggs collected from gravid O. mansoni females resulted the development of enough larvae to describe the development in intermediate hosts (Schwabe, 1951); although, levels of infection were not reported.

The morphology of L3 O. petrowi are similar to the descriptions of other L3 from within Thelaziidae. The best described examples are T. callipaeda in flies from the genus Phortica, O. mansoni from Surinam cockroach and $O$. conjunctivalis from Nauphoete cinerea (Schwabe, 1951; Otranto et al. 2005; Ivanova et al. 2007). Although we did observe 'sausage-like' larvae similar to the description of 
second stage $T$. callipaeda (Otranto et al. 2005), we were unable to verify any stage larvae were $O$. petrowi other than L3.

Our detection of eggs from feces at 52 dpi suggests development of $O$. petrowi is consistent with $O$. mansoni in chickens, which shedding in feces was detected 60 dpi (Sanders, 1928). The low levels of eggs detected by fecal flotation were an unexpected result. This low rate of shedding may indicate infection in the laboratory is not an accurate representation of a naturally occurring infection or Oxyspirura spp. shed low levels of eggs. In supporting the later, several previous experimental and field studies on O. mansoni in chickens have reported difficulty in collecting eggs from the feces and throughout the digestive tract (Fielding, 1927; Sanders, 1928; Schwabe, 1951).

There are other potential explanations for our low recovery of eggs from fecal samples. First, our fecal flotation technique may have not been sensitive enough. We do not think this is the case. Although other flotation techniques perform better when there is a high level of eggs (>100 eggs/g), the Cornell-Wisconsin double centrifugation technique has a high reported sensitivity ( $>90 \%$ ) for low egg/g (<7 eggs/g) counts (Egwang and Slocombe, 1981, 1982). Furthermore, the Cornell-Wisconsin method is recommended for samples were egg recovery is expected to be low, but the more commonly used McMaster technique and its variants have a higher analytical sensitivity (25 eggs/g; Zajac et al. 2012).

Another potential explanation for low egg recovery is the result of the immune response associated with the pen-raised northern bobwhites having an infection with an unidentified stongylid. The effects of multiple parasitic infections on hosts are largely understudied, but in wild animals multiple infections are considered the rule rather than the exception (Bordes and Morand, 2011). Although it is understudied, polyparasitism has been reported from northern bobwhites with no reported detrimental effects (Davidson et al. 1980, 1991). Therefore, the dual infection in our study could potentially be a closer representation to naturally infected northern bobwhites; however, effects of polyparasitsm are known to range from antagonistic to synergistic depending on the hosts and parasites involved (Tefler et al. 2010) and because all of our experimental infected birds had dual infections we were unable to evaluate if there was an effect on $O$. petrowi egg shedding.

Two previous studies on $O$. petrowi reported that blood was readily observed within the body of $O$. petrowi removed from wild quail species (Dunham et al. 2014, 2015). In our present study, we did not detect similar findings from any of the nematodes collected from experimentally infected birds. This may be related to $O$. petrowi only feeding on blood during certain times of its life cycle; however, we collected $O$. petrowi during different stages of development, including gravid females. Blood feeding at certain times in nematode development has been reported with Litomosoides sigmodontis (Attout et al. 2005) and we did not collect the samples to rule this possibility out for $O$. petrowi.

The results of this study add a valuable piece of information in our understanding of $O$. petrowi infections in northern bobwhites. These data suggest a potential model intermediate host species, which can be used to monitor how anthelminthic treatment of northern bobwhites affects the availability of $O$. petrowi in intermediate hosts. Furthermore, it provides an experimental infection technique that allows us to analyse the impacts $O$. petrowi infection has on individual birds, as well as, providing a means to perfect diagnostic tools (e.g. quantitative PCR) for identifying infection in wild birds antemortem. Future research is needed to determine the factors which influence shedding of $O$. petrowi eggs in northern bobwhites as well as the best biological samples to collect from birds for diagnostic assays.

\section{ACKNOWLEDGEMENTS}

We would like to thank Park Cities Quail for funding for this project, Spade Ranch for access to the field location, Brad Thomas for assistance with artwork and Dr Roy Berghaus for statistical guidance.

\section{F I NANCIAL SUPPORT}

Funding for this work was provided by Park Cities Quail (not awarded to any specific author).

\section{CONFLICTS OF INTEREST}

None.

\section{ETHICAL STANDARDS}

All animal use procedures were approved by the Texas Tech University Institutional Animal Care Use Committee (Protocol no. 13066-08).

\section{REFERENCES}

Addison, E. M. and Anderson, R. C. (1969). A review of eyeworms of the genus Oxyspirura (Nematoda: Spiruroidea). Wildlife Diseases No. 55, 58pp.

Attout, T., Babayan, S., Hoerauf, A., Taylor, D. W., Kozek, W. J., Martin, C. and Bain, O. (2005). Blood-feeding in the young adult filarial worms Litomosoides sigmodontis. Parasitology 130, 421-428.

Bordes, F. and Morand, S. (2011). The impact of multiple infections on wild animal hosts: a review. Infection Ecology \& Epidemiology 1, 7346.

Bright, K. L., Bernays, E. A. and Moran, V. C. (1994). Foraging patterns and dietary mixing in the field by the generalist grasshopper Brachystola magna (Orthoptera: Acrididae). Fournal of Insect Behavior 7, 779-793.

Bruno, A., Fedynich, A. M., Smith-Herron, A. and Rollins, D. (2015). Pathological response of northern bobwhites to Oxyspirura petrowi infections. Fournal of Parasitology 101, 364-368.

Brust, M., Thurman, J., Reuter, C., Black, L., Quartarone, R. and Redford, A. J. (2014). Grasshoppers of the western United States, 4th Edn. United States Department of Agriculture Animal and Plant Health 
Inspection Service Identification Technology Program, Fort Collins, Colorado, USA. http://idtools.org/id/grasshoppers

Burleson, W. H. (1974). A two-year life cycle in Brachystola magna (Orthoptera: Acrididae) with notes on rearing and food preference. Annals of the Entomological Society of America 67, 526-528.

Calegaro-Marques, C. and Amato, S. B. (2013). Seasonal influences on parasite community structure of Turdus rufiventris (Aves). The fournal of Parasitology 99, 1-5.

Dancak, K., Pence, D. P., Stormer, F. A. and Beasom, S. L. (1982). Helminths of the scaled quail, Callipepla squamata, from northwest Texas. Proceedings of the Helminthological Society of Washington 49, 144-146. Davidson, W. R., Kellogg, F. E. and Doster, G. L. (1980). Seasonal trends of helminth parasites of bobwhite quail. Fournal of Wildlife Diseases 16, 367-375.

Davidson, W. R., Kellogg, F. E., Doster, G. L. and Moore, C. T. (1991). Ecology of helminth parasitism in bobwhites from northern Florida. Fournal of Wildlife Diseases 27, 185-205.

Dunham, N. R., Soliz, L. A., Brightman, A., Rollins, D., Fedynich, A. M., and Kendall, R. J. (2015). Live eyeworm (Oxyspirura petrowi) extraction, in vitro culture, and transfer for experimental studies. Fournal of Parasitology 101, 98-101.

Dunham, N. R., Soliz, L. A., Fedynich, A. M., Rollins, D. and Kendall, R. J. (2014). Evidence of an Oxyspirura petrowi epizootic in northern bobwhites (Colinus virginianus), Texas, USA. Fournal of Wildlife Diseases 50, 552-558.

Egwang, T. G. and Slocombe, J. O. D. (1981). Efficiency and sensitivity of techniques for recovering nematode eggs from bovine feces. Canadian Fournal of Comparative Medicine 45, 243-248.

Egwang, T. G. and Slocombe, J. O. D. (1982). Evaluation of the CornellWisconsin centrifugal flotation technique for recovering Trichostrongylid eggs from bovine feces. Canadian Fournal of Comparative Medicine 46, 133-137. Fielding, J. (1927). Further observations on the life history of the eye worm of poultry. Australian Fournal of Experimental Biology and Medical Science 4, 273-281.

Harveson, L. A., Guthery, F. S. and Hellgren, E. C. (2004) Invertebrate consumption by breeding northern bobwhites and its relation to production. The Southwestern Naturalist 49, 472-477.

Host, C. T. O. and Physics, O. N. M. (2015). Ground-dwelling arthropod communities related to nesting success of northern bobwhite at two western Oklahoma wildlife management areas. Southwestern Entomologist 40, 463-478.

Ivanova, E., Spiridonov, S. and Bain, O. (2007). Ocular oxyspirurosis of primates in zoos: intermediate host, worm morphology, and probable origin of the infection in the Moscow zoo. Parasite (Paris, France) 14 $287-298$.

Johnson, J. A., Bellinger, M. R., Toepfer, J. E. and Dunn, P. (2004) Temporal changes in allele frequencies and low effective population size in greater prairie-chickens. Molecular Ecology 13, 2617-2630.

Judd, S. D. (1905). The Bobwhite and other Quails of the United States in their Economic Relations. Bureau of Biological Survey, Bulletin No. 21, Goverment Printing Office, Washington, DC.
Kobayashi, H. (1927). On the life history of Oxyspirura mansoni and pathological changes in the conjuctive and the dactus lacrymalis caused by the worm. Fapanese Pathological Society Transactions 17, 239-242.

Otranto, D., Lia, R. P., Cantacessi, C., Testini, G., Troccoli, A., Shen, J. L. and Wang, Z. X. (2005). Nematode biology and larval development of Thelazia callipaeda (Spirurida, Thelaziidae) in the drosophilid intermediate host in Europe and China. Parasitology 131, 847-855.

Parent, C. J., Hernández, F., Brennan, L. A., Wester, D. B., Bryant, F. C. and Schnupp, M. J. (2016). Northern bobwhite abundance in relation to precipitation and landscape structure. Fournal of Wildlife Management 80, 7-18

Parmalee, P. W. (1953). Food and cover relationships of the bobwhite quail in east-central Texas. Ecology 34, 758-770.

Pence, D. B. (1972). The genus Oxyspirura (Nematoda : Thelaziidae) from birds in Louisiana. Proceedings of the Helminthological Society of Washington 39, 23-28.

Pence, D. B. (1975). Eyeworms (Nematoda: Thelaziidae) from west Texas quail. Proceedings of the Helminthological Society of Washington 42, 181183.

Rho, P., Wu, X. B., Smeins, F. E., Silvy, N. J. and Peterson, M. J. (2015). Regional land cover patterns, changes and potential relationships with scaled quail (Callipepla squamata) abundance. Ecology and Environment 38, 185-193.

Robel, R. J., Walker, T. L., Hagen, C. A., Ridley, R. K., Kemp, K. E. and Applegate, R. D. (2003). Helminth parasites of lesser prairie-chicken Tympanuchus pallidicinctus in southwestern Kansas: incidence, burdens and effects. Wildlife Biology 9, 341-349.

Robel, R. J., Walker, T. L., Ridley, R. K., Kemp, K. and Applegate, R. D. (2005). Helminthic parasites in ring-necked pheasants from southwestern Kansas. Prairie Naturalist 37, 17-24.

Rollins, D. (1980). Comparative ecology of bobwhite and scaled quail in mesquite grassland habitats. M.S. thesis, Oklahoma State University, Stillwater, OK, USA.

Sanders, D. A. (1928). Manson's Eyeworm of poultry. Fournal of the American Veterinary Medical Association 25, 568-584.

Schwabe, C. W. (1951). Studies on Oxyspirura mansoni, the tropical eyeworm of poultry. II. Life history. Pacific Science 5, 18-35.

Tefler, S., Lambin, X., Birtles, R., Beldomenico, P., Burthe, S., Paterson, S. and Begon, M. (2010). Species interactions in a parasite community drive infection risk in a wildlife population. Science $\mathbf{3 3 0}$, 243-246.

Wood, K. N., Guthery, F. S. and Koerth, N. E. (1980). Spring-summer nutrition and condition of northern bobwhites in south Texas. Fournal of Wildlife Management 50, 84-88.

Xiang, L., Guo, F., Zhang, H., Lacoste, L., Rollins, D., Bruno, A., Fedynich, A. M. and Zhu, G. (2013). Gene discovery, evolutionary affinity and molecular detection of Oxyspirura petrowi, an eye worm parasite of game birds. BMC Microbiology 13, 233.

Zajac, A. M., Conboy, G. A., Greiner, E. C., Smith, S. A. and Snowden, K. F. (2012). Veterinary Clinical Parasitology, 8th Edn. John Wiley \& Sons Inc., West Sussex, UK. 